\title{
Segmented stochastic convengence across the G-7 countries
}

\author{
Roberto Cellini and Antonello E. Scorcu \\ (University of Bologna, D epartment of Economics) \\ August $18^{\text {th }}, 1998$
}

\begin{abstract}
This paper analyzes the stochastic convergence in per capita income levels among the current G - 7 over the period 1900-89. We show that, in the presence of possible structural breaks, the strong condition of stationary pair-wise differences between per capita GDP holds in many more cases than generally supposed. However, it occurs more frequently in the first part of the time sample than in the second one.
\end{abstract}

\section{JEL Classification 041}

Kegwards Cointegration, Structural break, Stochastic convergence.

\section{Adknoukedgments}

We are indebted to Roberto Golinelli, Renzo Orsi, Lucio Sarno and Vera Zamagni for helpful comments. We thank Cristina Polisi for the excellent assistance. The usual disclaimer applies. Research supported by the University of Bologna.

\section{ComespondingA uthor}

Antonello E. Scorcu,

Dipartimento di Scienze Economiche, Strada Maggiore, 45 - 40125 Bologna, Italy.

Tel. +39 51 6402611, Fax + 3951 6402664, Email <scorcu@ spbo.unibo.it>. 
Segmented stochastic convergence

across the G-7 countries

\section{Introduction}

In this paper we analyze the stochastic convergence in per capita output levels among the G-7 countries in the presence of structural breaks.

Stochastic convergence differs from beta-convergence, in so far as it does not evaluate whether less developed countries catch up with the richer ones, but it «essentially asks whether permanent movements in one country's per capita output are associated with permanent movements in another countries' output.» (Bernard and Durlauf, 1991, p. 2). Put differently, it examines, in a time-series analysis approach, whether common stochastic elements matter, and how much persistent the differences among countries are.

The available analyses show that in this century stochastic convergence is the exception rather than the rule in the OECD countries: the differences among these relatively homogeneous economies do not appear to vanish over time, in spite of the strong evidence of common stochastic elements driving the long-run patterns of per capita income levels. ${ }^{1}$ However, these studies do not take into account the possibility of structural breaks. Indeed, stochastic convergence tests refer to a situation in which the asymptotic distribution is closely approximated by the sampling distribution. The presence of a break, by definition, invalidates this assumption. Nevertheless, we find that the investigation about stochastic convergence allowing for regime shifts can shed light into the actual behavior of the economies and help understand the patterns of these countries' growth. Specifically, we analyze the (current) G-7 countries over the period 1900-1989, pair by pair.

The tests developed by Gregory and Hansen (1996) allow us to study the cases in which an endogenously selected break occurs in the intercept and/or in the slope coefficients of the cointegrating relationship. This is far from being a minor technical aspect, because it can reveal when stochastic convergence begins or/ and when it ceases. Moreover, convergence occurs more frequently when allowing for a structural break.

The necessary condition for stochastic convergence to hold is cointegration with vector $(1,-1)$. This paper considers the case that such a coinstrained cointegration holds at least for limited (though substantial) subperiods. D ata can reject this hypothesis only in 4 out of 21 possible country pairs. In 6 cases the constrained cointegration appears to hold over the whole period, in the presence of a change in the intercept term. In other 2 cases convergence holds until a year and since a subsequent year. In the remaining 9 cases, stochastic convergence appears to occur only until a given (estimated) year. The most astonishing evidence concerns the fact that in no cases the $(1,-1)$ cointegration appears to hold

${ }^{1}$ Bernard and Durlauf (1992, 1995), Campbell and Mankiw (1989) and Cogley (1990). 
only during the second half of the time sample. In other words, the increased economic integration among the G-7 countries (with the associated evidence of beta-convergence) does not appear to lead to stochastic convergence.

The paper is organized as follows. Section 2 briefly discusses the concept of stochastic convergence as well as the econometric tools used to analyze it in the presence of structural breaks. Section 3 describes the data and presents the results of the analysis. Section 4 comments and concludes.

\section{Stachasic convegenein thepresence of regimeshifts}

Consider the time series of per capita output of two countries, denoted by $\mathrm{Y}_{t}$ and $\mathrm{X}_{t}$, and assume that each of them is integrated of order one, i.e., $\mathrm{Y}_{\mathrm{t}} \mathrm{I}(1)$ and $\mathrm{X}_{\mathrm{t}} \mathrm{I}(1)$. Stochastic convergence occurs if at a given time $t$ the long-term forecast of the output level is the same for both countries: $\lim _{k \rightarrow \infty} E\left(Y_{t+k}-X_{t+k} \mid \Omega_{t}\right)=0$, with $\Omega_{t}$ denoting the information set at time t (Bernard and Durlauf, 1995). For stochastic convergence to occur the two series must cointegrate under the vector $(1,-1)$. O bviously, if $\left(\mathrm{Y}_{\mathrm{t}} \mathrm{X}_{\mathrm{t}}\right)$ contains either a non-zero mean or a unit root, then stochastic convergence fails to hold.

In order to test stochastic convergence we consider regression equation

$$
\text { [1] } Y_{t}=\alpha+\beta X_{t}+\varepsilon_{t} \quad \mathrm{t}=1, . ., \mathrm{T}
$$

and test for $\alpha=0, \beta=1$ and the stationarity of the residuals $\left\{\varepsilon_{t}\right\}$. It is clear that stochastic convergence can be meaningfully investigated if and only if one assumes that the data sample is generated by economies near their limiting distributions, and there is no transitional dynamics.

This paper aims at evaluating how the evidence of stochastic convergence changes, when taking into account the possibility of a structural break in the cointegrating relationship, at an unknown point in time. In particular we wish to consider situations in which a given cointegrating vector holds only over a sub-period. Moreover, we wish to investigate the possibility that the cointegrating vector with slopes $(1,-1)$ holds over the whole time period, but in the presence of a shift in the deterministic component of the series.

As is well known, if the static regression equation [1] gives stationary estimated residuals, then $\mathrm{X}$ and $\mathrm{Y}$ are cointegrated. Assume that this is not the case. Now consider a possible regime shift occurring at time $\tau$ (with $\tau=1, . ., \mathrm{T}$ ) and consider a dummy variable $\mathrm{D}_{\mathrm{t}}{ }^{\tau}$, such that:

$$
D_{t}^{\tau}=\left\{\begin{array}{l}
0 \text { if } t<\tau \\
1 \text { if } t>\tau
\end{array}\right.
$$

Let us consider a model in which the shift implies a change in the intercept term alone (equation [2]), or 
a model in which the shift implies a change in the intercept and the slope-coefficient (equation [3]):

[2] $\quad Y_{t}=a_{0}+a_{1} D_{t}^{\tau}+b X_{t}+s_{t}$

[3] $\quad Y_{t}=a_{0}+a_{1} D_{t}^{\tau}+b_{0} X_{t}+b_{1} D_{t}^{\tau} X_{t}+u_{t}$

If the series of the residuals $\left\{\zeta_{t}\right\}$ or $\left\{u_{t}\right\}$ are stationary, we can say that $X$ and $Y$ cointegrate in the presence of a regime shift, involving, respectively, the intercept alone or both the intercept and the slope. In both cases, the cointegrating vector has changed at time $\tau$, with $\mathrm{a}_{1}$ (or a1 and $\mathrm{b}_{1}$ ) measuring the shift(s) in the coefficient(s) since $\tau$.

Gregory and Hansen (1996) work out a procedure for the endogenous determination of $\tau$, testing for the stationarity of the residuals of the relationships [2] or [3]. The procedure prescribes: (i) to consider each possible value of $\tau$ in the reasonable range $0.15 \mathrm{~T}<\tau<0.85 \mathrm{~T}$, and to run the regression including the corresponding break; (ii) to compute the ADF-statistics or the Perron-Phillips $Z_{t}$ statistics based on the residuals series (needless to say, there is a different residuals series for each $\tau$ ); (iii) to choose the value of $\tau$ which gives the largest negative value for such statistics across all possible breakpoints. Formally, the value for the test statistics is $A D F^{*}=\inf _{\tau} A D F(\tau)$ or $Z_{t}^{*}=\inf _{\tau} Z(\tau)$. The $\mathrm{ADF}^{*}$ and $\mathrm{Z}^{*} \mathrm{t}$ statistics have the same asymptotic distribution, but the latter appears to perform better in small size samples, according to Montecarlo evidence.

In the present study we are interested in the following three cases:

- [case a] cointegration with vector $(1,-1)$ occurs over the whole sample period, with a change in the intercept term at a given year (to be estimated) in the sample;

- [case b] cointegration with vector $(1,-1)$ occurs only since a given year (to be estimated) in the sample;

- [case c] cointegration with vector $(1,-1)$ occurs only until a given year (to be estimated) in the sample. Consequently, in the following section we consider regression specifications imposing -rather than estimating- one coefficient of the cointegrating vector.

\section{Data and exidene}

We consider the real GDP per head, expressed in 1985 US 1000 dollars, for the US, Canada, Germany, France, UK, Italy and Japan over the period 1900-1989 (annual observations). We employ the data computed by St. Aubyn (1996), basing on Maddison (1991) and Summers and Heston (1991, version PWT 5.6). The series correspond to 1989 borders for all countries.

First of all, we test whether each series under examination contains a unit root. Table 1 shows that $\mathrm{ADF}$ test can not reject the presence of a unit root, even when a deterministic linear trend in DGP is 
considered. The presence of a unit root can not be rejected either over the period 1900-1938; this point will be important in the discussion below.

TABLE 1 - ADF test for the series of income level, 1900-1989 and 1900-1938.

\begin{tabular}{|l|l|l|l|l|l|l|l|}
\hline & \multicolumn{1}{|c|}{ US } & \multicolumn{1}{c|}{ CA } & \multicolumn{1}{c|}{ GE } & \multicolumn{1}{c|}{ FR } & \multicolumn{1}{c|}{ UK } & \multicolumn{1}{c|}{ IT } & \multicolumn{1}{c|}{ JA } \\
\hline $1900-1989$ & -2.595 & -0.014 & -0.808 & -0.921 & -0.382 & 0.190 & 1.236 \\
& $(-3.461)$ & $(-3.461)$ & $(-3.461)$ & $(-3.462)$ & $(-3.461)$ & $(-3.461)$ & $(-3.461)$ \\
\hline $1900-1938$ & -2.684 & -3.201 & -0.503 & -2.958 & -3.043 & -2.593 & -0.691 \\
& $(-3.535)$ & $(-3.535)$ & $(-3.531)$ & $(-3.547)$ & $(-3.539)$ & $(-3.535)$ & $(-3.531)$ \\
\hline
\end{tabular}

Notes: We consider a model with a constant and a linear trend in all cases. The lag length is chosen using the AIC. Critical value at the $95 \%$ confidence level in parenthesis.

Table 2 reports the results about pair-by-pair cointegration under the $(1,-1)$ cointegrating vector in the absence of structural break. Of course, Table 2 conveys the (already known) message of an impressive lack of convergence between the non-stationary stochastic components of the time series. Bernard and Durlauf (1991) find that only the pair France-Italy, among the G-7, can reject the presence of a unit root in the pair difference. We confirm this evidence about France-Italy, though with test statistics very near the critical value. We will see that the evidence of the $(1,-1)$ cointegration between France and Italy becomes more compelling when allowing for a shift in the intercept term.

We find that also US-JA and US-GE can reject the null of no-cointegration, according to the $\mathrm{Z}_{\mathrm{t}}$ test. As for the pair US-GE, we may repeat the point made in the IT-FR case: the evidence for cointegration becomes much more compelling when taking into account a shift in the intercept term. As for US-JA we obtain $\mathrm{ADF}_{1}=-1.889$ (critical value -2.894) that can not reject the no-cointegration. The different conclusions from $\mathrm{Z}_{t}$ and ADF tests may be due to the strong effect of the structural break.

TABLE 2 - Z tests for pair wise cointegration under vector (1,-1)

\begin{tabular}{|l|l|l|l|l|l|l|}
\hline & CA & GE & FR & UK & IT & JA \\
\hline US & -1.944 & $-2.970^{\#}$ & -2.028 & -1.492 & -1.984 & $-3.125^{\#}$ \\
\hline CA & & -0.928 & -0.855 & 1.471 & -0.519 & -2.439 \\
\hline GE & & & -2.587 & -1.297 & -2.081 & 0.021 \\
\hline FR & & & & -1.284 & $-3.073^{\#}$ & 0.212 \\
\hline UK & & & & & -1.030 & 4.327 \\
\hline IT & & & & & & 1.468 \\
\hline
\end{tabular}

Notes: We consider the regression $\mathrm{Y}_{\mathrm{t}}=\mathrm{a}+\mathrm{bX}+\mathrm{et}$ under the restriction $\mathrm{b}=1$, and test for the presence of a unit root in the residuals et using the $Z_{t}$ tests with window length 25 . The critical value at the $95 \%$ confidence level is -2.895; superscript \# denotes significance.

Let us test for cointegration in the presence of a regime shift regarding the intercept term alone. We consider the [case a] outlined in Section 2, and take into account the following regression specification:

[4] $\quad Y_{t}=\alpha_{0}+\alpha_{1} D_{t}^{\tau}+\beta X_{t}+\varepsilon_{t}, \quad \mathrm{t}=\{1900, \ldots, 1989\}, \tau=\{1914, \ldots, 1976\}$

under the restriction $\beta=1$. For each country pair we consider all possible regression equations 
corresponding to the 63 possible positions of one single break between 1914 and 1976. ${ }^{2}$

Results are summarized in Table 3. Each cell of the Table corresponds to a country pair and reports the $\mathrm{Z}_{\mathrm{t}}^{*}$ statistics, along with the corresponding $\tau$. Such $\tau$ represents the estimated position of the single break, and is associated with the strongest evidence in favor of stationary residuals in regression with intercept shift. The $\mathrm{ADF}^{*}$ statistics provide analogous evidence and are not reported for the sake of brevity. ${ }^{3}$

TABLE 3 - The $\mathrm{Z}^{*}$ tstatistics under [case a]

\begin{tabular}{|l|l|l|l|l|l|l|}
\hline & CA & GE \#\# & FR & UK & IT & JA \\
\hline US & -3.315 & -7.884 & -3.969 & -3.677 & $-6.420 \#$ & -3.457 \\
& $(1972)$ & $(1938)$ & $(1938)$ & $(1944)$ & $(1938)$ & $(1968)$ \\
\hline CA & & -2.870 & -2.499 & -2.515 & -2.125 & -4.550 \\
& & $(1971)$ & $(1976)$ & $(1966)^{\# \#}$ & $(1938)_{\# \#}$ & $(1936)$ \\
\hline GE & & & -3.252 & $-6.7699^{\#}$ & $-6.523^{\# \#}$ & -2.484 \\
& & & $(1936)$ & $(1962)$ & $(1932)^{\# \#}$ & $(1974)$ \\
\hline FR & & & & -3.645 & -6.054 & -2.331 \\
& & & & $(1958)$ & $(1954)$ & $(1976)$ \\
\hline UK & & & & & -3.630 & -1.945 \\
& & & & & $(1959)$ & $(1972)$ \\
\hline IT & & & & & & -2.095 \\
& & & & & & $(1976)$ \\
\hline
\end{tabular}

Notes: The Table reports $Z_{t}^{*}=\inf _{\tau \in[1914,1976]} Z_{t}(\tau)$ and the corresponding $\tau$ for each country pair, at the window length 25 . The critical value is -4.61 at the $95 \%$ confidence level and -4.34 at the $90 \%$ confidence level. Superscripts ${ }^{\#}$ and ${ }^{\#}$ denote significance at the $5 \%$ level and 10\% level, respectively.

Let us consider now the shifts in the intercept and the slope coefficient, requiring that the cointegrating vector $(1,-1)$ holds only starting from year $\tau$. This corresponds to the [case b] of Section 2 . Formally, we consider:

$$
Y_{t}=\alpha_{0}+\alpha_{1} D_{t}^{\tau}+\beta_{0}\left(1-D_{t}^{\tau}\right) X_{t}+\beta_{1} \cdot D_{t}^{\tau} X_{t}+u_{t}, \mathrm{t}=\{1900, \ldots, 1989\}, \tau=\{1914, \ldots, 1976\}
$$

under the restriction $\beta_{1}=1$, and test for the stationarity of $u_{t}$ across the 63 possible positions of the break between 1914 and 1976 in each of the 21 country pairs. Table 4 reports the results.

TABLE 4 - The $\mathrm{Z}_{\mathrm{t}}^{*}$ statistics under [case b]

\begin{tabular}{|c|c|c|c|c|c|c|}
\hline & $\mathrm{CA}$ & $\mathrm{GE}$ & FR & UK & IT & $\mathrm{JA}$ \\
\hline US & $\begin{array}{l}-5.120^{\# \#} \\
(1969)\end{array}$ & $\begin{array}{l}-7.937^{\# \#} \\
(1938)\end{array}$ & $\begin{array}{l}-3.983 \\
(1938)\end{array}$ & $\begin{array}{l}-5.692^{\# \#} \\
(1963)\end{array}$ & $\begin{array}{l}-6.287^{\# \#} \\
(1938)\end{array}$ & $\begin{array}{l}-3.457 \\
(1961)\end{array}$ \\
\hline CA & & $\begin{array}{l}-2.943 \\
(1971)\end{array}$ & $\begin{array}{l}-2.490 \\
(1976)\end{array}$ & \begin{tabular}{|l}
-4.091 \\
$(1969)$
\end{tabular} & $\begin{array}{l}-2.275 \\
(1971)\end{array}$ & $\begin{array}{l}-4.619 \\
(1936)\end{array}$ \\
\hline $\mathrm{GE}$ & & & $\begin{array}{l}-3.160 \\
(1937)\end{array}$ & $\begin{array}{l}-7.435 \\
(1962)\end{array}$ & $\begin{array}{l}-8.377^{\# \#} \\
(1932)\end{array}$ & \begin{tabular}{|l}
-2.759 \\
$(1972)$
\end{tabular} \\
\hline
\end{tabular}

21914 and 1976 correspond to $0.15 \mathrm{~T}$ and $0.85 \mathrm{~T}$, respectively.

3 The AD F* statistics, like the other results mentioned but not printed in the paper, are available upon request. 


\begin{tabular}{|l|l|l|l|l|l|l|}
\hline FR & & & & -3.814 & $-5.9755^{\# \#}$ & $\begin{array}{l}-2.442 \\
(1957) \\
\end{array}$ \\
\hline UK & & & & & -3.478 & -1.987 \\
& & & & & $(1956)$ & $(1972)$ \\
\hline IT & & & & & & -2.046 \\
& & & & & & $(1976)$ \\
\hline
\end{tabular}

Notes: The Table reports $Z_{t}^{*}=\inf _{\tau \in[1914,1976]} Z_{t}(\tau)$ and the corresponding $\tau$ for each country pair, at the window length 25 . The critical value is -4.95 at the $95 \%$ confidence level and -4.68 at the $90 \%$ confidence level. Superscripts ${ }^{\circ}$ and ${ }^{\#}$ denote significance at the $5 \%$ and $10 \%$ level, respectively.

Finally we consider [case c] that imposes the $(1,-1)$ cointegrating vector only until a point of time in the available sample. We run the regression:

[6] $\quad Y_{t}=\alpha_{0}+\alpha_{1} D_{t}^{\tau}+\beta_{0}\left(1-D_{t}^{\tau}\right) X_{t}+\beta_{1} D_{t}^{\tau} X_{t}+w_{t}, \mathrm{t}=\{1900, \ldots, 1989\}, \tau=\{1914, \ldots, 1976\}$

under the restriction $\beta_{0}=1$, and test for the stationarity of we. Results are reported in Table 5.

TABLE 5 - The $\mathrm{Z}^{*}$ tstatistics under [case c]

\begin{tabular}{|c|c|c|c|c|c|c|}
\hline $\mathrm{USS}_{\mathrm{US}}$ & \begin{tabular}{|l|} 
CA \\
$-5.576 \# \#$ \\
\end{tabular} & \begin{tabular}{|l|} 
GE \\
$-9890^{\# \#}$ \\
\end{tabular} & \begin{tabular}{|l|l|} 
FR \\
-57704
\end{tabular} & $\begin{array}{l}\text { UK } \\
-5050 \#\end{array}$ & \begin{tabular}{|l|} 
IT \\
$-7651^{\# \#}$
\end{tabular} & \begin{tabular}{|l}
$\mathrm{JA}$ \\
-9712
\end{tabular} \\
\hline US & & $\begin{array}{l}-9.890 \\
(1938)\end{array}$ & $\begin{array}{l}-5 . / 04 \\
(1938)\end{array}$ & $\begin{array}{l}-5.050 \\
(1938)\end{array}$ & - & $\mid \begin{array}{l}-9.712 \\
(1938)\end{array}$ \\
\hline$\overline{\mathrm{CA}}$ & & \begin{tabular}{|l|}
-4.165 \\
$(1938)$
\end{tabular} & $\begin{array}{l}-3.219 \\
(1933)\end{array}$ & $\begin{array}{l}-5.109 \text { \#\# } \\
(1941)\end{array}$ & \begin{tabular}{|l}
-7.488 \\
$(1937)$
\end{tabular} & $\begin{array}{l}-8.681 \\
(1938)^{\#}\end{array}$ \\
\hline$\overline{\mathrm{GE}}$ & & & $\begin{array}{l}-4.995 \\
(1939)\end{array}$ & $\begin{array}{l}-7.178 \text { \#\# } \\
(1962)\end{array}$ & \begin{tabular}{|l}
-6.306 \\
$(1935)$
\end{tabular} & $\begin{array}{l}-4.922^{\#} \\
(1944)\end{array}$ \\
\hline \begin{tabular}{|l|l} 
RR \\
\end{tabular} & & & & $\begin{array}{l}-3.318 \\
(1933)\end{array}$ & $\begin{array}{l}-5.820 \# \# \\
(1954)^{\#}\end{array}$ & \begin{tabular}{|c|}
-3.789 \\
$(1957)$
\end{tabular} \\
\hline \begin{tabular}{|l|l} 
UK \\
\end{tabular} & & & & & $\begin{array}{l}-5.581 \# \# \\
(1935)\end{array}$ & $\begin{array}{l}-7.452 \\
(1945)\end{array}$ \\
\hline IT & & & & & & $\begin{array}{l}-6.530 \\
(1950)\end{array}$ \\
\hline
\end{tabular}

Notes: The Table reports $Z_{t}^{*}=\inf _{\tau \in[1914,1976]} Z_{t}(\tau)$ and the corresponding $\tau$ for each country pair, at the window length 25. The critical value is -4.95 at the $95 \%$ confidence level and -4.68 at the $90 \%$ confidence level. Superscripts $\#$ and ${ }^{\#}$ denote significance at the $5 \%$ and $10 \%$ level respectively.

The conclusions emerging from Tables 3 to 5 are summarized in Table 6, which shows whether, and possibly when, the $(1,-1)$ cointegration vector holds. (The null hypothesis is always the presence of a unit root in the static regression residuals; accordingly, we should correctly say that our tests reject, or do not reject, the null of no-cointegration.) WHOLE indicates that such constrained cointegration holds over the whole period, with a shift in the intercept alone (the year when such a break is estimated to occur is reported in parenthesis). TILL indicates that data support the cointegration under vector (1,1) in the initial part of the period. SINCE indicates that data support cointegration under the $(1,-1)$ vector in the final part of the period. Both the TILL and the SINCE cases imply also a possible shift in the constant term. NO indicates that the cointegration relation $(1,-1)$ never holds. 
Noteworthy, the cases where the constrained cointegration never appears to hold are only 4 out of 21: CA-GE, FR-CA, FR-UK and FR-JA. In the remaining 17 cases, cointegration appears to hold either over the whole period under scrutiny, or over shorter (though substantial) time periods.

For six pairs - namely: US-GE, US-IT, CA-JA, GE-UK, GE-IT, FR-IT - the (1,-1) cointegrating vector holds over the whole period. It is not surprising that in such cases, Tables 4 and 5 support the cointegration with vector $(1,-1)$ since a year and till a year, respectively. These years coincide or are very close each other, and both coincide or are very close to the year indicated by Table 3 for the break in the intercept alone. In other words, in these cases constrained cointegration under [case a] consistently encompasses constrained cointegration under cases [b] and [c]. This element strengthens the reliability of our estimation procedure.

For two pairs, US-CA and US-UK, we can not reject the cointegration with the $(1,-1)$ vector both until a year and since a not-close, following year. However, and consistently, cointegration with the $(1,-1)$ vector over the whole period does not appear to hold.

Finally, for 9 pairs, the $(1,-1)$ cointegrating vector appears to hold exclusively since 1900 until a year usually located just before or just after the World War II. Put differently, in the majority of cases, the necessary condition for stochastic convergence to hold, ceases in the proximity of WWII.

TABLE 6 - When the $(1,-1)$ cointegration holds.

\begin{tabular}{|c|c|c|c|c|c|c|}
\hline & CA & GE & FR & UK & IT & JA \\
\hline US & $\begin{array}{c}\text { TILL 1943 and } \\
\text { SINCE 1969 }\end{array}$ & $\begin{array}{c}\text { WHOLE } \\
\text { (c.s. 1938) }\end{array}$ & TILL 1938 & $\begin{array}{c}\text { TILL 1938 and } \\
\text { SINCE 1963 }\end{array}$ & $\begin{array}{c}\text { WHOLE } \\
\text { (c.s. 1938) }\end{array}$ & TILL 1938 \\
\hline CA & & NO & NO & TILL 1941 & TILL 1937 & $\begin{array}{c}\text { WHOLE } \\
\text { (c.s. 1936) }\end{array}$ \\
\hline GE & & & TILL 1939 & $\begin{array}{c}\text { WHOLE } \\
\text { (c.s. 1962) }\end{array}$ & $\begin{array}{c}\text { WHOLE } \\
\text { (c.s. 1932) }\end{array}$ & TILL 1944 \\
\hline FR & & & & NO & $\begin{array}{c}\text { WHOLE } \\
\text { (c.s. 1954) }\end{array}$ & NO \\
\hline UK & & & & & TILL 1935 & TILL 1935 \\
\hline IT & & & & & & TILL 1950 \\
\hline
\end{tabular}

Notes: See text. c.s. in parenthesis stands for «constant shift in year ...»

O ur evidence suggests that the supposed increased integration among the G-7 economies over the last four or five decades did not lead to stronger convergence among the stochastic components of per capita income levels. This is not at variance with the evidence of beta-convergence within the $\mathrm{G} 7$ group (Baumol, 1986). Indeed, the economic integration after WWII, joint with the remarkable technological progress, led industrialized countries to an exceptional average growth in current productivity levels until the beginning of the Seventies (Temin, 1997). Technological progress might have determined an even more marked increase of the potential output of these countries. The consequences could be large opportunities for catching-up and, at the same time, a failure of stochastic convergence across 
countries. ${ }^{4}$

We would like to stress three points. First, as these tests can detect only one break, multiple regime shifts are not allowed. Loosely speaking, this should not be a problem, since a unimodal distribution for $Z_{t}(\tau)$ emerges in most cases. Second, the presence of a unit root in each series of the income level over the limited period 1900-38 can not be rejected (see Table 1). This suggests that the massive evidence of constrained cointegration during the first part of the sample does not derive from the stationarity of the series during that sub-period. Third, structural breaks make cointegration easier to obtain i.e. lower the number of common trends driving the output levels series within the group of G-7.

So far we have not considered the estimates of the intercept terms. Table 7 reports such estimates for the six pairs revealing cointegration under [case a] or, equivalently, under equation (4). Remember that $\alpha 1$ captures the shift in the intercept term. The t-statistics show that $\alpha_{0}$ and $\left(\alpha_{0}+\alpha_{1}\right)$ can not be considered to be equal to zero. In the unique not self-evident case, GE-UK, a $\chi^{2}$ test on the restriction $\left(\alpha_{0}+\alpha_{1}\right)=0$ gives $\chi^{2}(1)=9.696$, leading to reject the restriction.

TABLE 7 - Intercepts' estimates for pairs rejecting the hypothesis of no-cointegration under equation [4].

\begin{tabular}{|l|l|l|l|}
\hline Pair & $\tau$ & $\alpha_{0}$ & $\alpha_{1}$ \\
\hline US-GE & 1938 & 2.474 & 1.703 \\
& & $(16.955)$ & $(8.874)$ \\
\hline US-IT & 1938 & 2.816 & 2.579 \\
& & $(19.635)$ & $(13.669)$ \\
\hline CA-JA & 1936 & 1.954 & 1.459 \\
& & $(14.760)$ & $(8.539)$ \\
\hline GE-UK & 1962 & -1.602 & 1.920 \\
& & $(-23.328)$ & $(15.596)$ \\
\hline GE-IT & 1932 & 0.305 & 0.844 \\
& & $(3.557)$ & $(7.903)$ \\
\hline FR-IT & 1954 & 0.668 & 0.598 \\
& & $(12.115)$ & $(6.852)$ \\
\hline
\end{tabular}

Notes: The Table reports the estimates (and the relative tstatistics in parenthesis) of $\alpha_{0}$ and $\alpha_{1}$ in equation [4], considering the value of $\tau$ which gives the $Z^{*}$ t statistics leading to reject the null of no-cointegration.

It is important to notice that in all the cases considered in Table 7, but the pair GE-UK, the difference between the constant terms of the series has increased, rather than decreased during the second half of the century. Moreover, the shift in the intercept for the pair FR-IT is significant: this leads us to dismiss the previous (tentative) conclusion that France and Italy converge over the whole period without any regime shift.

Table 8 reports the estimates of the intercept term for pairs accepting the $(1,-1)$ cointegrating vector only over limited sub-period(s). We show the estimates of the intercept term of the (constrained) static

${ }^{4}$ As is well known, beta-convergence refers to countries in transition to their steady states, whereas stochastic convergence assumes countries to be in steady state. We suggest that the transition has been more important in 
regression over the sub-sample in which the $(1,-1)$ cointegration relationship holds, according to Table 6. Note that all the «SINCE» regressions considered in Table 8 can count on at least 31 observations. In all cases the constant term appears to be different from zero at the usual confidence level.

TABLE 8 - Intercept term estimates when the $(1,-1)$ cointegration holds over a limited period.

\begin{tabular}{|l|l|l|l|l|l|l|}
\hline Pair & Sample & Intercept & Pair & Sample & Intercept \\
\hline US-CA & $1900-1943$ & $\begin{array}{l}1.795 \\
(21.414)\end{array}$ & & GE-JA & $1900-1944$ & $\begin{array}{l}1.292 \\
(18.777)\end{array}$ \\
\hline US-FR & $1900-1938$ & $\begin{array}{l}2.154 \\
(28.499)\end{array}$ & & UK-IT & $1900-1935$ & $\begin{array}{l}1.926 \\
(48.963)\end{array}$ \\
\hline US-UK & $1900-1938$ & $\begin{array}{l}0.868 \\
(8.815)\end{array}$ & & UK-JA & $1900-1945$ & $\begin{array}{l}2.867 \\
(42.086)\end{array}$ \\
\hline US-JA & $1900-1938$ & $\begin{array}{l}3.602 \\
(43.138)\end{array}$ & & IT-JA & $1900-1950$ & $\begin{array}{l}0.753 \\
(18.647)\end{array}$ \\
\hline CA-UK & $1900-1941$ & $\begin{array}{l}-0.819 \\
(-13.867)\end{array}$ & & & & \\
\hline CA-IT & $1900-1937$ & $\begin{array}{l}1.143 \\
(22.706)\end{array}$ & & US-CA & $1969-1989$ & $\begin{array}{l}1.428 \\
(9.687)\end{array}$ \\
\hline GE-FR & $1900-1939$ & $\begin{array}{l}-0.278 \\
(-5.460)\end{array}$ & US-UK & $1963-1989$ & $\begin{array}{l}4.190 \\
(47.351)\end{array}$ \\
\hline
\end{tabular}

Note: t-statistics in parenthesis.

Table 8, like Table 7, suggests a very simple story: differences in income levels are far from being nil, even when levels cointegrate with vector $(1,-1)$. Income levels may be hit by the same stochastic shock, but the deterministic component of the series differ markedly. Such a difference prevents the possibility of having equal income levels, at least in finite sample.

\section{Comments and condudingremarks}

A number of papers, relying on time series analysis, documented an impressive failure of the stochastic convergence in per capita income levels among the largest OECD countries over the last century.

We have reconsidered these analyses allowing for shifts in the cointegrating relationships. We have documented that the strong condition of cointegration under the vector $(1,-1)$ is very likely to occur, at least for long (though limited) periods of time. Surprisingly, the golden period for such constrained cointegration appears to be the first half of the century, rather than the second one.

While one could question the consistency of our regressions with the inner significance of stochastic convergence, which makes sense in so far as data at hand are under their limiting distribution, we find that this evidence can provide new insight in understanding the growth patterns of the G-7 countries.

Provided that structural breaks are important, the interpretation of growth patterns based on a number of stable common trends could be flawed. We prefer to support an interpretation whereby two 
different regimes are in fact present: in the first half of the Twentieth century countries were likely to be near their limiting distributions, and stochastic convergence emerges neatly. During the second half of the century transition processes are likely to be more important. This is consistent with the clear emergence of beta-convergence joint with a weak evidence of stochastic convergence. 


\section{References}

BAUMOL William J. (1986), «Productivity Growth Convergence, and Welfare: What the Long Run D ata Show», American EconomicReview vol. 76, pp.1072-85.

BERNARD Andrew B. - DURLAUF Steven N. (1991), «Convergence of International Output Movements», NBER Working Paper No. 3717.

BERNARD Andrew B. - DURLAUF Steven N. (1995), «Convergence in International O utput», Jaumal of Applied Ecommatris vol. 10, pp. 97-108.

BERNARD Andrew B. - DURLAUF Steven N. (1996), «Interpreting Tests of the Convergence Hypothesis», Jaumal of Ecomamerics vol. 71, pp. 161-73.

CAMPBELL John Y. - MANKIW Gregory N. (1989), «International Evidence on the Persistence of Economic Fluctuations», Jaumal of Montary Econamics vol. 23, pp. 319-33.

COGLEY Timothy (1990), «International Evidence on the Size of the Random Walk in Output», Jaumal of Pditical Econamy, vol.. 98, pp. 501-18.

GREGORY Allan W. - HANSEN Bruce E. (1996), «Residual-Based Tests for Cointegration in Models with Regime Shifts», Jaumal of Econamerics, vol. 70, pp. 99-126.

MADDISON Angus (1991), Dynamic Fores in Capitalist Dedeqment. A LongRun Comparative Viev Oxford University Press, Oxford.

ST. AUBYN Miguel (1996), «Convergence across Industrialized Countries (1980-1989): New Results Using Time Series Methods», Cadernos de Economicas, Universitade Tecnica de Lisboa, No. 2/ 96.

SUMMERS Robert - HESTON Alan (1991), «The Penn World Table (Mark 5): An Expanded Set of International Comparisons, 1950-1988», QuartelyJaumal of Ecomamics vol. 106, pp. 327-68.

TEMIN Peter (1997), «The Golden Age of European Growth: A Review Essay», European Review of EconamicHistary, vol. 1, pp. 127-49. 